\title{
Temperature-touch interactions: Is there a reverse Weber phenomenon?
}

\author{
ROLF J. ZIMMERMANN and JOSEPH C. STEVENS \\ John B. Pierce Foundation Laboratory and Yale University, New Haven, Connecticut 06519
}

\begin{abstract}
Recent studies have confirmed and extended the 19th-century observations of E. H. Weber that concomitant cold can intensify the apparent heaviness of tactile pressure stimulation. These studies have also shown that concomitant warm can also intensify pressure sensation in some regions of the body. The question arises whether pressure can intensify thermal sensations under comparable conditions of stimulation. Subjects made magnitude estimations of the thermal sensations aroused at eight different temperatures and at three different forces. Estimated thermal sensation turned out to be independent of the force level. Such an outcome strengthens the argument against the hypothesis that thermal intensification represents a central summation of thermal and tactile sensations.
\end{abstract}

In 1846, E. H. Weber reported that a cold Thaler (a 19th-century German coin approximately the size of an American silver dollar) placed on the forehead feels at least as heavy as two warm ones, one on top of the other. More than a century later, Jones, Singer, and Twelker (1962) used the method of magnitude estimation to look for possible temperature-touch interactions. They used a stimulator of $.4 \mathrm{~cm}^{2}$ in area that was cooled or warmed to $9^{\circ} \mathrm{K}$ below or above skin temperature and pressed on the skin with different forces to cause intrusions of $1.5 \mathrm{~mm}$. Their only significant finding was a slight tendency for intermediate but not extremely cold stimuli to be judged colder when accompanied by greater pressure. Neither warmth nor cold influenced perceived touch, nor did pressure influence warmth or strong cold.

The apparent discrepancy between 19th- and 20thcentury reports led Stevens (1979) and Stevens and Green (1978) to a set of experiments that reinvestigated the influence of concomitant warmth or cold on the sensation of pressure. The stimuli, aluminum blocks of various weights $(10-1,810 \mathrm{~g})$, various sizes $\left(.4-\right.$ to $29-\mathrm{cm}^{2}$ surface), and various temperatures $\left(0^{\circ}-45^{\circ} \mathrm{C}\right)$, were applied to seven different body regions. The subjects were asked to judge the apparent heaviness by magnitude estimation. The results show a marked intensification of touch magnitude by concomitant cold in all body regions (under the best conditions, a cold 10-g weight matched a 100-g weight at skin temperature). A smaller increase by warmth occurred in some body

This research was supported by NIH Grant R01 NS 15419 and by Studienstiftung des Deutschen Volkes. Requests for reprints should be sent to Joseph C. Stevens, John B. Pierce Foundation, 290 Congress Avenue, New Haven, Connecticut 06519 , or to Rolf Zimmermann, Physiologisches Institut der Philipps-Universität, Deutschhausstrasse 2, 3550 Marburg, West Germany. regions (e.g., forearm), but not in others (e.g., forehead). For the smallest area $\left(.4 \mathrm{~cm}^{2}\right)$, interactions appeared almost negligible, indicating that the earlier attempts to reproduce Weber's findings probably failed because they used too small an area.

Since the recent studies of the Weber phenomenon were published, the question has frequently arisen whether, under roughly equivalent conditions of stimulation, pressure can enhance thermal sensation. In other words, are there symmetrical interactions between touch and temperature? The present note describes an experiment designed to answer this question.

\section{METHOD}

Paid volunteers (11 female, 11 male), mostly college students, served as subjects in an experiment using magnitude estimation of temperature sensation. Aluminum blocks (19 x $38 \times 31 \mathrm{~mm})$, cooled or warmed in regulated water baths of eight different temperatures $\left(4^{\circ}, 12^{\circ}, 20^{\circ}, 24^{\circ}, 28^{\circ}, 36^{\circ}, 40^{\circ}, 44^{\circ} \mathrm{C}\right)$, were placed at three different forces $(.62,2.3,7.7 \mathrm{~N})$ for $3 \mathrm{sec}$ on the volar surface of the forearm. The force was varied by means of a calibrated spring tension gauge attached to the top of the aluminum block. Each of the 24 stimuli was applied twice to the same subject (once to the right and once to the left arm), in a pseudorandom order and at a rate of 1 stimulus/min. The area of each stimulus was $19 \times 38 \mathrm{~mm}\left(7.2 \mathrm{~cm}^{2}\right)$, which was about the largest area that would grant complete contact between stimulator and skin for the smallest applied pressure (the weight of the block itself). The subjects were instructed to estimate the apparent strength of the thermal sensation, both warmth and cold, on a common scale of sensory intensity, by giving numbers proportional to the apparent strength of the thermal sensation. The number zero was to be used only if no temperature could be perceived at all; otherwise, the subjects were free to use any positive numbers they thought appropriate. Between stimulations, the skin temperature was normalized by 30 -sec application of a $3 \times 6 \mathrm{~cm}$ thermode of $33^{\circ} \mathrm{C}$.

\section{RESULTS}

The geometric means of the estimates are shown in 


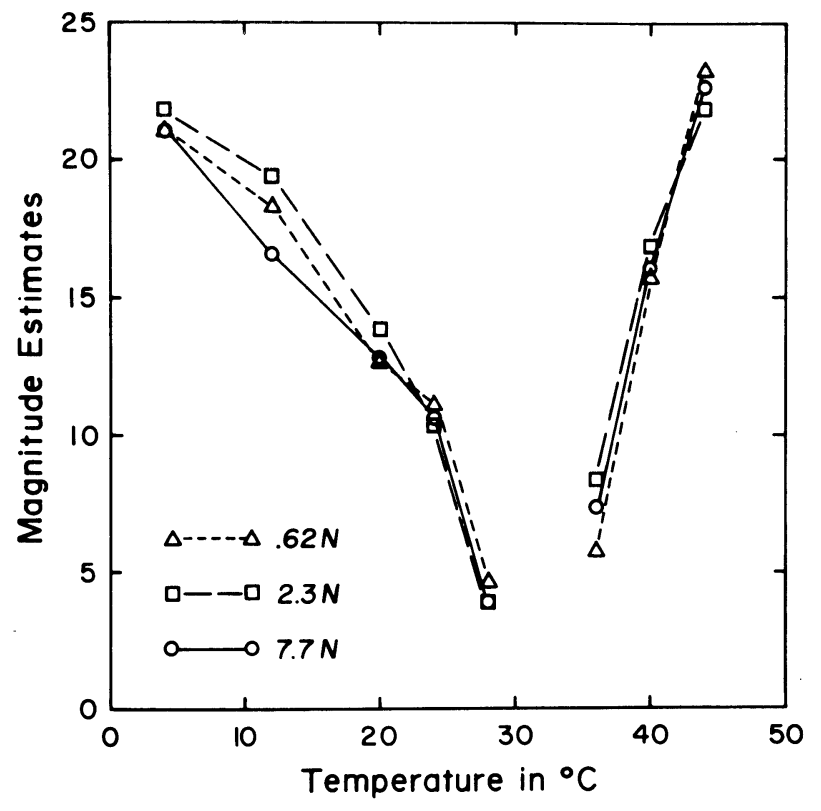

Figure 1. Geometric means of magnitude estimates of perceived thermal intensity as a function of the temperature of the stimulator. The parameter is the concomitant force.

Figure 1. Although it is obvious to visual inspection that pressure matters little or not at all, the data were subjected to $t$ tests for paired data and to analyses of variance, operating on the logarithms of the estimates. Both types of test failed to reveal any systematic influence of pressure on thermoperception.

\section{DISCUSSION}

The effect of concomitant pressure on temperature sensation was investigated earlier by McFarland (1971). In a set of experi- ments, McFarland instructed his subjects to judge the apparent thermal intensity of 16 stimuli that were combinations of four temperature changes $\left(1.0^{\circ}-4.0^{\circ} \mathrm{K}\right.$ below skin temperature) and four pressures (skin indentations of $.5-3.0 \mathrm{~mm}$ ). The surface area of the stimulator was $.13 \mathrm{~cm}^{2}$. McFarland found a tendency for cold to be judged greater when accompanied by higher pressure. This effect was limited to the two lowest levels of pressure, and it was even demonstrable when the thermal and the tactile stimuli were separated spatially or temporally and, therefore, must have been caused at a level of the nervous system higher than that of the peripheral receptors. In all cases, however, the effect was only slight.

When the area is greater and all stimuli are well above the central threshold, temperature-touch interaction can be profound but is plainly asymmetric: Tactile sensations can be greatly influenced by temperature; the perception of thermal stimuli, however, is essentially independent of concomitant pressure under comparable conditions of stimulation. This is difficult to reconcile with the hypothesis that the Weber phenomenon is due to a central summation of thermal and tactile sensations, but instead, it adds another line of support to the theory that the interaction is caused by an imperfect stimulus selectivity of mechanoreceptors (Stevens \& Green, 1978).

\section{REFERENCES}

Jones, F. N., Singer, D., \& Twelker, P. A. Interactions among the somesthetic senses in judgments of subjective magnitude. Journal of Experimental Psychology, 1962, 64, 105-109.

McFARLAND, R. A. Enhancement of thermal estimates by concomitant pressure stimulation. Journal of Experimental Psychology, 1971, 88, 20-25.

Stevens, J. C. Thermal intensification of touch sensation: Further extensions of the Weber phenomenon. Sensory Processes, 1979, 3, 240-248.

Stevens, J. C., \& Green, B. G. Temperature-touch interaction: Weber's phenomenon revisited. Sensory Processes, 1978, 2, 206-219.

Weber, E. H. Der Tastsinn und das Gemeingefuhl. In R. Wagner (Ed.), Handworterbuch der Physiologie (Vol. 3). Braunschweig: Vieweg, 1846.

(Received for publication March 10, 1982.) 